\title{
Sustainable production of furfural and 5-hidroximetilfurfural from rice husks and soybean peel by using ionic liquid
}

\author{
Elisandra SCAPIN ${ }^{1,2,3 *}$ (D), Magale Karine Diel RAMBO ${ }^{2}$, Guenther Carlos Couto VIANA ${ }^{1}$, Nicole MARASCA ${ }^{1}$, \\ Gabriela Eustáquio LACERDA ${ }^{4}$, Michele Cristiane Diel RAMBO ${ }^{5}$, Rachel de Moura Nunes FERNANDES ${ }^{1,3}$
}

\begin{abstract}
In the current search for renewable energy sources, residual biomass has been highlighted as a potential source of chemical compounds that are currently obtained from petroleum. Among the derivatives obtained from this, 5-hydroxymethylfurfural and furfural are considered key parts in this process as they are key compounds in the fine chemical industry. This work aims at the use of the rice husks and soybean peel for the synthesis of 5-hydroxymethylfurfural and furfural using the ionic liquid [BMIM][Br]. The physical pre-treatment of biomasses was carried out followed by acid hydrolysis. For the synthesis of the furanic compounds, different temperatures and reaction times were used. The products obtained in each step were analyzed by infrared spectrophotometry and by high performance liquid chromatography. The best yields for rice husks was obtained with 4 hours of reaction at $120^{\circ} \mathrm{C}(34 \%)$ and for soy peel with 3 hours of reaction at $120^{\circ} \mathrm{C}(59 \%)$, for furfural production. For 5-hydroxymethylfurfural production the yields were $8.7 \%$ and $3.4 \%$ for rice and soy husks, respectively. It was found that glucose was the main group related to bio-products obtaining.
\end{abstract}

Keywords: furanic compounds; raw biomass; agricultural waste; green solvents.

Practical Application: This work aims at the use of rice husks and soybean peel, residual biomasses increasingly produced in Brazil, for the synthesis of 5-hydroxymethylfurfural and furfural using the ionic liquid [BMIM][Br]. The work emphasizes the use of residual biomasses, which are discarded in the majority of the time, in the use of chemical platforms of extreme importance in the world scenario. And it also highlights the use of ionic liquid, a green solvent, as a reaction solvent/catalyst for increasing the yield of the obtained products.

\section{Introduction}

The production of biochemicals and energy production from sustainable biomass have seen increasing interest due the positive effect on the environment, since it can decrease $\mathrm{CO}_{2}$ emissions and atmospheric pollution (Chheda et al., 2007).

The current commercial production of 5-hydroxymethylfurfural (HMF) and furfural predominantly relies on the syrups extracted from energy crops (Rosatella et al., 2011; van Putten et al., 2013; Klãusli, 2014). Several renewable biomass resources which are alternative feedstock enables more sustainable manufacturing practice (Chen et al., 2017; Nguyen et al., 2016; Yu et al., 2017). From lignocellulosic biomass wastes, HMF can be obtained from cellulose, while furfural can be recovered from hemicelluloses (pentoses xylose and arabinose) (Rosatella et al., 2011; Zhang et al. 2017). Both products are promising and typical platform chemicals that can be produced from the direct acid-catalyzed dehydration of biomass sugars (van Putten et al., 2013; Chen et al., 2017; Wang et al., 2017; Kong et al., 2018).

Furfural (2-furaldehyde) is an important chemical solvent used in petroleum refining or as starting material for the preparation of other organic solvents such as furfural alcohol and tetrahydrofuran. The furfural derivatives also have a high demand for using in the plastic, herbicides, food, pharmaceutical and agricultural industries (Dias et al., 2006, 2007; Ribeiro et al., 2012). Furfural was included among the top 30 added-value chemicals from biomass (Werpy et al., 2004). HMF is also one of the top biomass derived biochemical that can be converted into many promising derivatives, for example, 2,5-dimethyltetrahydrofuran, ethoxymethylfurfural, 2,5-furandicarboxylic acid, furfuryl alcohol, dimethylfuran, and 2,5-diformylfuran (Mitra et al., 2015; Mukherjee et al., 2015a; Rout et al., 2015). These chemicals serve as the building blocks of diverse commodities, including pharmaceuticals, polymers, resins, solvents, fungicides, and biofuels (Rosatella et al., 2011; van Putten et al., 2013; Yu et al., 2017; Galaverna \& Pastre, 2017; Kong et al., 2018).

To facilitate the conversion of hemicellulose and cellulose to HMF and furfural, respectively, ionic liquids (ILs) were used as solvent. They are useful, because they improved the conversion and selectivity, leading to improvements with respect to energy savings when they are compared to conventional solvents 
(Stark, 2011). The decreased energy consumption results from the improved catalytic ability, and/or by the implementation of efficient processing technologies. Moreover, the ionic character of the ILs can play a positive role in enhancing the catalytic activity and the reaction selectivity (Olivier-Bourbigou et al., 2010), as well as in stabilizing the reactive catalytic species and/or the reaction intermediates (Zhang et al., 2011; Li \& Yang, 2014).

Agricultural residues, such as rice hulls and soybean hulls, generated in large quantities in Brazil, are among the main sources used to obtain furfural and HMF, since they are rich in hemicellulose and cellulose (with approximately $20 \%$ and $36 \%$ respectively for rice husks, and $23 \%$ and $35 \%$ for soy peel) (Rambo et al., 2015).

The objective of the present work was to develop a simple method for production of furfural and HMF from lignocellulosic biomass hydrolysis. The effects of ILs use conditions (e.g., temperature and reaction time) on experimental results were also explored.

\section{Materials and method}

\subsection{Samples}

One sample of each biomass (soy peel and rice husks) was obtained as waste from a local production farm, later they were cleaned and separated manually. As a physical pre-treatment step, the soy peel and rice husks were milled by using knives mill (22 mesh) (Start FT 50 - Fortinox).

\subsection{Proximate analysis}

The ash content was determined according to the ASTM D3174-04 (American Society for Testing) in furnace for $600^{\circ} \mathrm{C}$ at 6 hours.

\subsection{Soxhlet extraction}

Approximately $1 \mathrm{~g}$ of rice husks and soy peel were extracted using Soxhlet ethanol apparatus. The best conditions were used according to Rambo et al. (2016), where short reaction times (5h), associated with high solvent concentrations (95\%), lead to higher yields.

\subsection{Cellulose, hemicellulose and lignin analysis}

The acid detergent fiber (FDA) and cold neutral detergent (FDN) according Trujillo et al. (2010), and NREL methodologies (National Renewable Energy Laboratory, 2019) were using to determine lignin, cellulose and hemicellulose content.

\subsection{Acid hydrolysis}

The acid hydrolysis was performed according to the adapted methodology developed by Browning (1967), $2 \mathrm{~g}$ of each sample was weighed, and for that mass $10 \mathrm{~mL}$ of $72 \%$ sulfuric acid was added in a glass beaker. The mixture was brought to the water bath (Fisatom, 550, Brazil) at $50^{\circ} \mathrm{C}$ for 7 minutes under constant stirring by using the glass stick. $40 \mathrm{~mL}$ of distilled water was added to stop the reaction, and the entire contents were placed in a $250 \mathrm{~mL}$ Erlenmeyer flask and autoclaved (Prismatec, CS) for 15 minutes at $121{ }^{\circ} \mathrm{C}$. After cooling, the solid fraction was separated from the liquid fraction using centrifuge at $2000 \mathrm{RPM}$ for 1 hour, then the liquid fraction was withdrawn with the aid of a glass pipette and solid fraction was washed and filtered on filter paper. The liquid fraction of the hydrolyzate was used for the synthesis of bioproducts.

\subsection{Synthesis of the ionic liquid [BMIM] [Br]}

The ionic liquid 1-n-butyl-3-methyl-imidazole bromide, [BMIM] $[\mathrm{Br}]$, was synthesized by the reaction with bromobutane and 1-methyimidizole in three round neck bottom flasks fitted with a reflux condenser for $48 \mathrm{~h}$ at $70^{\circ} \mathrm{C}$ with stirring according to the methodology of Dharaskar et al. (2016).

\subsection{Synthesis of 5-HMF and furfural}

The synthesis of HMF and furfural was performed according to the methodology Yi et al. (2012), where in a round bottom flask was added $5 \mathrm{~mL}$ of the hydrolyzate, $2 \mathrm{~g}$ of ionic liquid in an oil bath at 100,120 and $140{ }^{\circ} \mathrm{C}$ for reaction times of $1,2,3$ and 4 hours kept under reflux. After completion of the reaction time, the sample was washed with ethyl acetate three times.

\subsection{FT-IR spectroscopy}

The infrared spectrometer (FT-IR CARY 630, Agilent Technologies) with range of 650 to $4000 \mathrm{~cm}^{-1}$, with $0.4 \mathrm{~nm}$ of increment and 32 scans of averaging was used for analyzed all the samples (feedstock raw, hydrolyzed and after LI reaction).

\subsection{HPLC analysis}

To determine the HMF and furfural of the hydrolyzate and the samples after the reaction with ionic liquid was carried out by using Phenomenex Luna C18 $5 \mu(2)(250 \times 4.6 \mathrm{~mm})$ and pre-column Phenomenex C18 ( 4 × $3.0 \mathrm{~mm}$ ) filled with material similar to the main column. The eluent flow was $1 \mathrm{~mL} / \mathrm{min}$ at $30^{\circ} \mathrm{C}$, with a total run time of 15 minutes. The isocratic elution with a solution of acetonitrile/water (1:8 with $1 \%$ acetic acid) the detector used was UV (SPD-10A) with wavelength at $276 \mathrm{~nm}$. The yields of these compounds were calculated using the Equations 1 and 2:

HMF yield $(\mathrm{mol} \%)=\frac{(\mathrm{HMF} \text { concentration } * \text { liquid volume }) / 126}{\text { Grams of cellulose } / 162} * 100$

FF yield $($ mol $\%)=\frac{(\text { FF concentration } * \text { liquid volume }) / 96}{\text { Grams of hemicellulose } / 132} * 100$

\subsection{Statistical analysis}

Statistical analyses were carried out using Unscrambler (v 10.5, Camo Software, Oslo, Norway). All data collected were organized in plots and figures with Origin 8.0 (Northampton, MA, USA). 


\section{Results and discussion}

The Figure 1 shows the chemical analysis of the soy peel and rice husks.

The lignin content is the major component in both biomasses. The low ash content is important for the bio-products formation. Extractives may have an influence on bio-refining technologies and storage dynamics of biomass, interfering in the acid hydrolysis procedure and give inaccurate results for the bio-products. However, the low values found for extractives (11.9 and 11.6\%) for rice husks and soy peel, respectively, in this study does not indicate the need for removal (Browning, (1967).

Intermediate conditionalities were required for products optimization (Figure 2). For rice husks the best yield was obtained with 4 hours of reaction at $120^{\circ} \mathrm{C}$ and for soy peel with 3 hours of reaction at $120^{\circ} \mathrm{C}$, with respectively $34 \%$ and $59 \%$ of furfural production. High temperatures decrease the FF yield (12.7 and 3.5\%) for rice husks and soy peel, respectively.

For HMF production the best yields (8.7 and 3.4\%) respectively for rice and soy husks, were obtained with only 1 hour of reaction at $140{ }^{\circ} \mathrm{C}$ for both biomasses. Long reaction times $(>3 \mathrm{~h}$ ) decreased the yield of HMF less than $1.0 \%$. The low yield can be attributed to parallel reactions that occur in the acid hydrolysis or the most probable that has occurred is the levulinic acid and formic acid production (Bevilaqua et al., 2013; Mukherjee et al., 2015b).

Another reason for the higher yield of furfural, when it is compared to HMF, is that robust crystalline cellulose is far less reactive than amorphous hemicellulose; thus, furfural formation occurs much sooner than 5-HMF production in conventional catalytic systems. Therefore, the development of a single catalytic system for the production of both furfural and 5-HMF from raw biomass is still challenging (Mazzotta et al., 2014).

Others studies such as (Zhang \& Zhao, 2010) obtained under the optimal conditions furfural yield $25 \%$, which is close to the estimated value, $34 \%$ for this rice husks specie. Peleteiro et al. (2016), in a review speaking from furfural production using ionic liquids, the selective production of furfural from native lignocellulosic material using ILs obtained values ranging from $0.1-36 \%$. Normally high values of furfural $(>15 \%)$ are associated with separate reactions to obtain HMF and furfural. A single

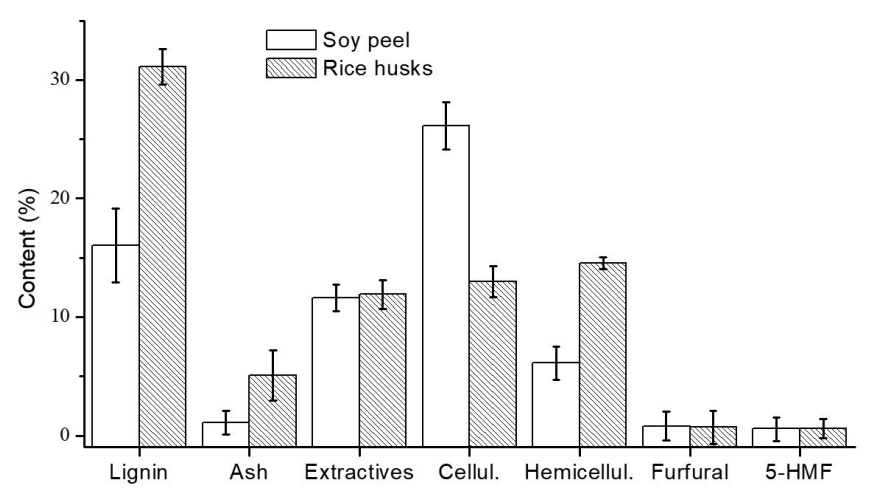

Figure 1. Descriptive statistics of the raw biomasses. reaction to obtain the two bio-products leads to limited yields. According to Girisuta et al. (2013), 50\% of the pentoses are converted to furfural.

The FTIR spectra of samples after the acid hydrolysis and after the liquid ionic treatment are shown in Figure 3. It is possible to check that changes occurred in the chemical structures of both biomasses after the ILs application. The peak at $3340 \mathrm{~cm}^{-1}$ is assigned to $\mathrm{O}-\mathrm{H}$ bonding in cellulose, appearing only in the hydrolyzed biomass. The partial removal of cellulose is associated with the reduction of intensity of this peak in the biomass treated with liquid ionic. Bands at $1600-1500 \mathrm{~cm}^{-1}$ in the hydrolyzed are characteristic from aromatic skeletal vibrations in lignins. The intensity of the peak at $1600 \mathrm{~cm}^{-1}$ for the biomasses treated with IL disappears, thus revealing the removal of lignin after the treatment using IL. Peaks pertaining to hemicellulose and cellulose $\left(1157 \mathrm{~cm}^{-1}, 1160 \mathrm{~cm}^{-1}, 1040-1060 \mathrm{~cm}^{-1}\right)$ show increased absorbance after the pretreatment (Figure $3 \mathrm{~B}$ ). The band at $1730 \mathrm{~cm}^{-1}$ after the IL reaction is assigned to $\mathrm{C}=\mathrm{O}$ groups in acetyl and uronic ester groups of hemicellulose (unconjugated $\mathrm{C}=\mathrm{O}$ stretch in xylans), which demonstrates that the reaction with IL made this band more prominent, favoring the release of xylose and, consequently, the formation of furfural. The bands at $1250 \mathrm{~cm}^{-1}$ and $1374 \mathrm{~cm}^{-1}$ are reported as being of stretch C-O of ether bonds from alkyl ester of the acetyl group and C-H deformation, both originating of hemicelluloses (Kumar et al., 2009; Naik et al., 2010; Banerjee et al., 2014).

It is seen that the treatment with IL favored hemicellulose, making its derivatives more prominent, which is clearly seen in a higher yield of furfural than 5-HMF (Figure 2).
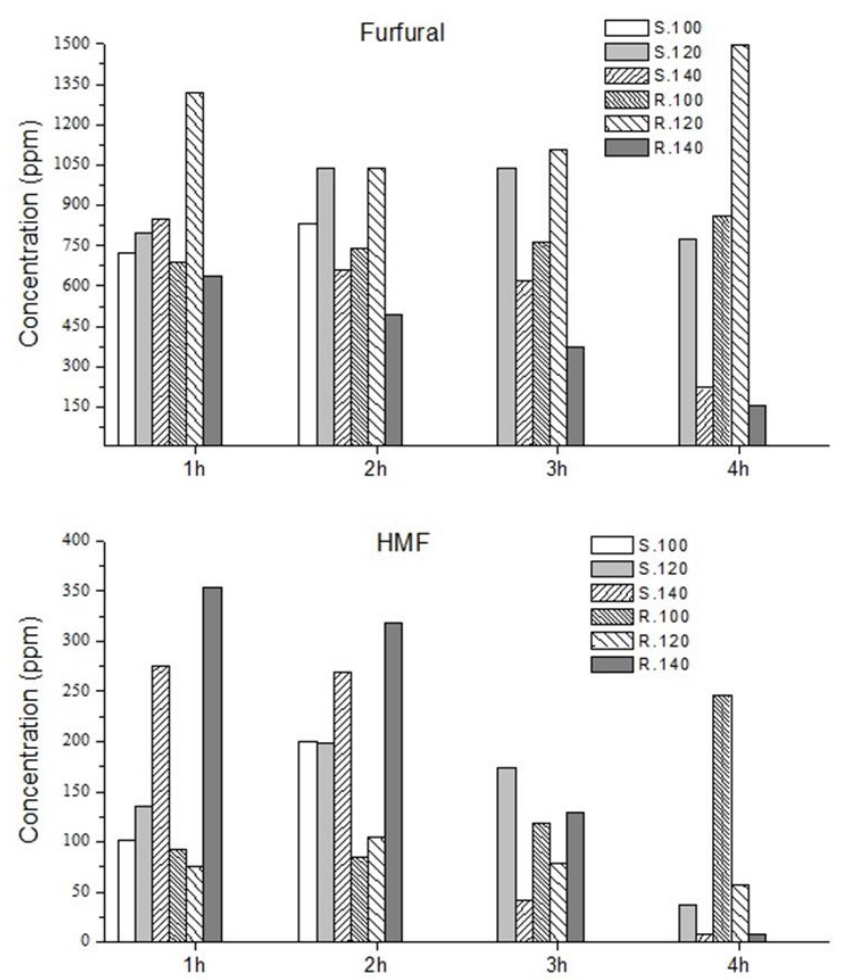

Figure 2. Effect of time and temperature in furfural and HMF concentration. (where S.: soy peel, R.: rice husks). 

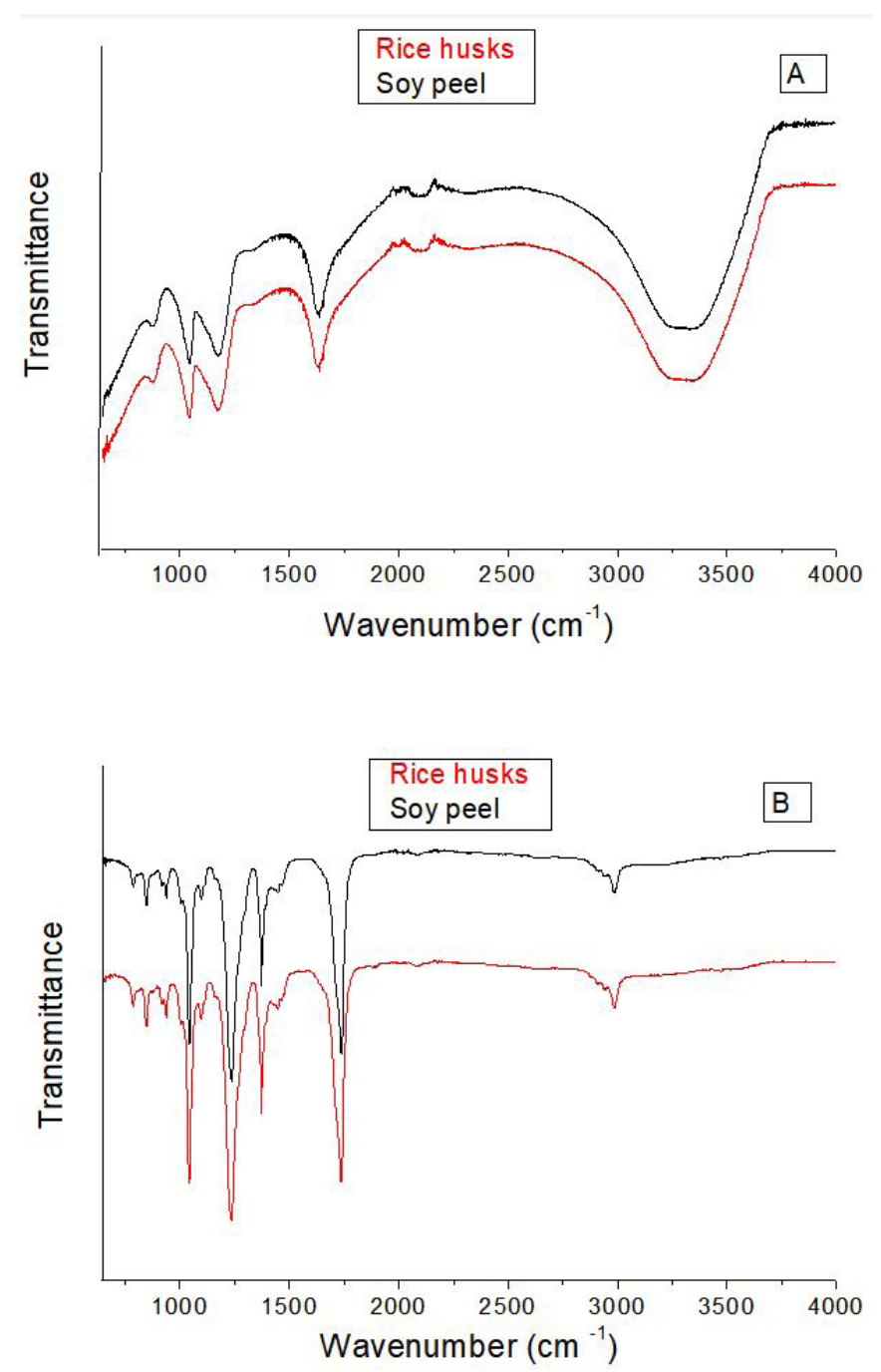

Figure 3. The FTIR spectra of (A) raw hydrolyzed and (B) hydrolyzed with liquid ionic.

\section{Conclusion}

Residual biomasses of soybean hulls and rice husks, coming from crops increasingly produced in Brazil, appear as promising raw materials for the synthesis of furanic compounds of high commercial value such as 5-HMF and furfural. One of the reasons for the low yields of 5-HMF and furfural is probably due to the high content of extractives present in the two biomasses during the acid hydrolysis. The use of the ionic liquid as a solvent is advantageous because it is a green, non-polluting solvent and can be reused at the end of each reaction. In addition, a large increase in HMF and furfural concentration was observed after the reaction using the ionic liquid [BMIM] [Br], thus demonstrating its efficiency in the conversion of sugars into furanic compounds. Comparing the best yields between the biomasses, it was concluded that for HMF production, as well as for furfural production, the rice husk showed higher concentrations. However, there is still a need for further studies aimed at optimizing the hydrolysis process and the synthesis reaction for the production of 5-HMF and furfural in high yields.

\section{Acknowledgements}

The authors thank the Federal University of Tocantins (UFT) for its financial support by the Productivity Research Program (n 17/2018), the Federal Institute of Tocantins- (IFTO) (No 51/2018) by the Research Support Program - PAP/ INOVA, the Post-graduate Program in Biodiversity and Biotechnology - BIONORTE for the technical support and financial and the Conselho Nacional de Desenvolvimento Científico e Tecnológico (CNPq).

\section{References}

Banerjee, C., Ghosh, S., Sen, G., Mishra, S., Shukla, P., \& Bandopadhyay, R. (2014). Study of algal biomass harvesting through cationic cassia gum, a natural plant based biopolymer. Bioresource Technology, 151, 6-11. http://dx.doi.org/10.1016/j.biortech.2013.10.035. PMid:24189379.

Bevilaqua, D. B., Rambo, M. K. D., Rizzetti, T. M., Cardoso, A. L., \& Martins, A. F. (2013). Cleaner production: levulinic acid from rice husks. Journal of Cleaner Production, 1, 1-6. http://dx.doi. org/10.1016/j.jclepro.2013.01.035.

Browning, B. L. (1967). Methods of wood chemistry (Vol. 1, 498 p.). New York: Wiley \& Sons, Interscience Publishers.

Chen, S. S., Maneerung, T., Tsang, D. C. W., Ok, Y. S., \& Wang, C.-H. (2017). Valorization of biomass to hydroxymethylfurfural, levulinic acid, and fatty acid methyl ester by heterogeneous catalysts. Chemical Engineering Journal, 328, 246-273. http://dx.doi.org/10.1016/j. cej.2017.07.020

Chheda, J. N., Roman-Leshkov, Y., \& Dumesic, J. A. (2007). Production of 5-hydroxymethylfurfural and furfural by dehydration of biomassderived mono-and poly-saccharides. Green Chemistry, 9(4), 342-350. http://dx.doi.org/10.1039/B611568C.

Dharaskar, S. A., Wasewar, K. L., Varma, M. N., Shende, D. Z., \& Yoo, C. K. (2016). Synthesis, characterization and application of 1-butyl-3methylimidazolium tetrafluoroborate for extractive desulfurization of liquid fuel. Arabian Journal of Chemistry, 9(4), 578-587. http:// dx.doi.org/10.1016/j.arabjc.2013.09.034.

Dias, A. S., Lima, S., Brandão, P., Pillinger, M., Rocha, J., \& Valente, A. A. (2006). Liquidphase dehydration of D-xylose over microporous and mesoporous niobium silicates. Catalysis Letters, 108(3-4), 179186. http://dx.doi.org/10.1007/s10562-006-0046-6.

Dias, A. S., Lima, S., Pillinger, M., \& Valente, A. A. (2007). Modified versions of sulfated zirconia as catalysts for the conversion of xylose to furfural. Catalysis Letters, 114(3-4), 151-160.

Galaverna, R., \& Pastre, J. C. (2017). Produção de 5-(Hidroximetil) furfural a partir de biomassa: desafios sintéticos e aplicações como bloco de construção na produção de polímeros e combustíveis líquidos. Revista Virtual de Química, 9(1), 248-273. http://dx.doi. org/10.21577/1984-6835.20170017.

Girisuta, B., Dussan, K., Haverty, D., Leahy, J. J., \& Hayes, M. H. B. (2013). A kinetic study of acid catalysed hydrolysis of sugar cane bagasse to levulinic acid. Chemical Engineering Journal, 217, 61-70. http://dx.doi.org/10.1016/j.cej.2012.11.094.

Klãusli, T. (2014). AVA biochem: commercializing renewable platform chemical 5-HMF. Green Process Synthesis, 3(3), 235-236. http:// dx.doi.org/10.1515/gps-2014-0029.

Kong, X., Zhu, Y., Fang, Z., Kozinski, J. A., Butler, I. S., Xu, L., Song, H., \& Wei, X. (2018). Catalytic conversion of 5-hydroxymethylfurfural to some value-added derivatives. Green Chemistry, 20(16), 36573682. http://dx.doi.org/10.1039/C8GC00234G. 
Kumar, R., Mago, G., Balan, V., \& Wyman, C. E. (2009). Physical and chemical characterizations of corn stover and poplar solids resulting from leading pretreatment technologies. Bioresource Technology, 100(17), 3948-3962. http://dx.doi.org/10.1016/j.biortech.2009.01.075. PMid:19362819.

Li, H., \& Yang, S. (2014). Catalytic transformation of fructose and sucrose to HMF with proline-derived ionic liquids under mild conditions. International Journal Of Chemical Engineering: Hindawi Publishing Corporation, 7, 978-708. http://dx.doi.org/10.1155/2014/978708.

Mazzotta, M. G., Gupta, D., Saha, B., Patra, A. K., Bhaumik, A., \& Abu-Omar, M. M. (2014). Efficient solid acid catalyst containing Lewis and Brønsted acid sites for the production of furfurals. ChemSusChem, 7(8), 2342-2350. http://dx.doi.org/10.1002/ cssc.201402007. PMid:24807741.

Mitra, J., Zhou, X., \& Rauchfuss, T. (2015). Pd-C-catalyzed reactions of HMF: decarbonylation, hydrogenation, and hydrogenolysis. Green Chemistry, 17(1), 307-313. http://dx.doi.org/10.1039/C4GC01520G.

Mukherjee, A., Dumont, M. J., \& Raghavan, V. (2015a). Review: sustainable production of hydroxymethylfurfural and levulinic acid: challenges and opportunities. Biomass and Bioenergy, 72, 143-183. http://dx.doi.org/10.1016/j.biombioe.2014.11.007.

Mukherjee, K., Bhattacharyya, S., \& Peralta-Yahya, P. (2015b). GPCRbased chemical biosensors for medium-chain fatty acids. ACS Synthetic Biology, 4(12), 1261-1269. http://dx.doi.org/10.1021/ sb500365m. PMid:25992593.

Naik, S. N., Goud, V. V., Rout, P. K., \& Dalai, A. K. (2010). Production of first and second generation biofuels: a comprehensive review. Renewable \& Sustainable Energy Reviews, 14(2), 578-597. http:// dx.doi.org/10.1016/j.rser.2009.10.003.

National Renewable Energy Laboratory - NREL. (2019). Determination of structural carbohydrates end lignin in biomass. Available from https://www.nrel.gov/

Nguyen, C. V., Lewis, D., Chen, W.-H., Huang, H.-W., ALOthman, Z. A., Yamauchi, Y., \& Wu, K. C.-W. (2016). Combined treatments for producing 5-hydroxymethylfurfural (HMF) from lignocellulosic biomass. Catalysis Today, 2, 344-349. http://dx.doi.org/10.1016/j. cattod.2016.03.022.

Olivier-Bourbigou, H., Magna, L., \& Morvan, D. (2010). Ionic liquids and catalysis: recent progress from knowledge to applications. Applied Catalysis, 373(1-2), 1-56. http://dx.doi.org/10.1016/j. apcata.2009.10.008.

Peleteiro, S., Rivas, S., Alonso, J. L., Santos, V., \& Parajó, J. C. (2016). Furfural production using ionic liquids: a review. Bioresource Technology, 202, 181-191. http://dx.doi.org/10.1016/j.biortech.2015.12.017. PMid:26708486.

Rambo, M. K. D., Almeida, K. J. C. R., Rambo, M., \& Baruque, E. A., Fo. (2016). The Response Surface Methodology as a tool to optimize the extraction and acid hydrolysis processes applied to babassu residues. Revista Brasileira de Pós-Graduação, 13, 807. http://dx.doi. org/10.21713/2358-2332.2016.v13.953.

Rambo, M. K. D., Schmidt, F. L., \& Ferreira, M. M. C. (2015). Analysis of the lignocellulosic components of biomass residues for biorefinery opportunities. Talanta (Oxford), 144, 696-703. http://dx.doi. org/10.1016/j.talanta.2015.06.045. PMid:26452879.

Ribeiro, P. R., Carvalho, J. R. M., Geris, R., Queiroz, V., \& Fascio, M. (2012). Furfural - da biomassa ao laboratório de química orgânica. Quimica Nova, 35(5), 1046-1051. http://dx.doi.org/10.1590/S010040422012000500033.
Rosatella, A. A., Simeonov, S. P., Frade, R. F. M., \& Afonso, C. A. M. (2011). 5-Hydroxymethylfurfural (HMF) as a building block platform: biological properties, synthesis and synthetic applications. Green Chemistry, 13(4), 754-793. http://dx.doi.org/10.1039/c0gc00401d.

Rout, P. K., Nannaware, A. D., Prakash, O., Kalra, A., \& Rajasekharan, R. (2015). Synthesis of hydroxymethylfurfural from cellulose using green processes: a promising biochemical and biofuel feedstock. Chemical Engineering Science, 142, 318-346. http://dx.doi.org/10.1016/j. ces.2015.12.002.

Stark, A. (2011). Ionic liquids in the biorefinery: a critical assessment of their potential. Energy \& Environmental Science, 4(1), 19-32. http://dx.doi.org/10.1039/C0EE00246A.

Trujillo, A. I., Marichal, M.J., \& Carriquiry, M. (2010). Comparison of dry matter and neutral detergent fiber degradation of fibrous feedstuffs as determined with in situ and in vitro gravimetric procedures. Animal Feed Science and Technology, 161(1-2), 49-57. https://doi.org/10.1016/j.anifeedsci.2010.08.001.

van Putten, R.-J., van der Waal, J. C., de Jong, E., Rasrendra, C. B., Heeres, H. J., \& de Vries, J. G. (2013). Hydroxymethylfurfural, a versatile platform chemical made from renewable resources. Chemical Reviews, 113(3), 1499-1597. http://dx.doi.org/10.1021/ cr300182k. PMid:23394139.

Wang, Q., Zhuang, X., Wang, W., Tan, X., Yu, Q., Qi, W., \& Yuan, Z. (2017). Rapid and simultaneous production of furfural and celluloserich residue from sugarcane bagasse using a pressurized phosphoric acid-acetone-water system. Chemical Engineering Journal, 2(9), 2022-2028. https://doi.org/10.1016/j.cej.2017.10.089.

Werpy, T. A., Holladay, J. E., \& White, J. F. (2004). Top value added chemicals from biomass: results of screening for potential candidates from sugars and synthesis gas (Vol. 1., 76 p.). NEREL http://dx.doi. org/10.2172/926125.

Yi, Y., Ha, M., Lee, J., \& Chung, C. (2012). New role of choromium fluoride: its catalytic action on the synthesis of hydroxymethylfurfural in ionic liquid using raw plant biomass and characterization of biomass hydrolysis (Vol. 180, pp. 370-375). Busan, South Korea: Chemical Engineering Journal.

Yu, I. K. M., Tsang, D. C. W., Yip, A. C. K., Chen, S. S., Wang, L., Ok, Y. S., \& Poon, C. S. (2017). Catalytic valorization of starch-rich food waste into hydroxymethylfurfural (HMF): controlling relative kinetics for high productivity. Bioresource Technology, 237, 222-230. http://dx.doi.org/10.1016/j.biortech.2017.01.017. PMid:28111030.

Zhang, L., Xi, G., Zhang, J., Yu, H., \& Wang, X. (2017). Efficient catalytic system for the direct transformation of lignocellulosic biomass to furfural and 5-hydroxymethylfurfural. Bioresource Technology, 224, 656-661. http://dx.doi.org/10.1016/j.biortech.2016.11.097. PMid:27913172.

Zhang, L., Zhao, H., Gan, M., Jin, Y., Gao, X., Chen, Q., Guan, J., \& Wang, Z. (2011). Application of simultaneous saccharification and fermentation (SSF) from viscosity reducing of raw sweet potato for bioethanol production at laboratory, pilot and industrial scales. Research Support, 21(6), 277-777. http://dx.doi.org/10.1016/j. biortech.2010.12.115. PMid:21277777.

Zhang, Z., \& Zhao, Z. K. (2010). Microwave-assisted conversion of lignocellulosic biomass into furans in ionic liquid. Bioresource Technology, 101(3), 1111-1114. http://dx.doi.org/10.1016/j. biortech.2009.09.010. PMid:19800219. 